\title{
Adenocarcinoma of Meibomian glands in Male- A rare case report \\ Siddiqi $\mathrm{MH}^{1}$, Huq $\mathrm{MH}^{2}$, Begum $\mathrm{A}^{3}$, Fazilatunnesa ${ }^{4}$.
}

\begin{abstract}
A 50 years old male presented with recurrent multinodular growth on the right upper eyelid mimicking multiple chalazion for the last two years. He was treated as chalazion two times but recurred. A full thickness wide excisional biopsy of the lesion along with normal lid tissue done. Histopathological report was Adenocarcinoma of the meibomian gland of the right upper lid. Lid reconstruction done by lid sharing procedure. Result of the treatment was excellent after follow up period of six months with good lid function and no significant complication.
\end{abstract}

CBMJ 2013 Jan: Vol-02, No-01: P: 69-72

Key words: Meibomian gland adencarcinoma, chalazion, Histopathology.

\section{Introduction}

Adenocarcinoma of the meibomian glands of the eyelid in male is very rare with high mortality rate and malignancy ${ }^{1}$. Meibomian glands are modified sebaceous glands. Although sebaceous glands are present throughout the body they are common in ocular region (about $75 \%)^{2}$. The most common site of origin of ocular sebaceous carcinoma are meibomian gland, Gland of Zeis, lacrimal gland, curuncle etc.(1.5-5\%of all malignant eyelid neoplasms) ${ }^{3,4}$. This type of tumor most frequently occur in female and on the upper eyelid of elderly patients ${ }^{5,6,7,8}$. It is invariably mistaken for Chalazion but may also mimic as Basal cell carcinoma, Squamous cell carcinoma, Blepharoconjunctivitis or Malignant Melanoma. After incision \& curettage the tumor grow rapidly and spread to neighibouring lymph nodes especially preauricular.

The prognosis of such case is poor because of frequent misdiagnosis, high recurrence rate,malignancy, mortality and metastasis. ${ }^{1,9}$. So early diagnosis, wide lid excision with lid reconstruction may result good prognosis. Radiotherapy may be helpful if surgery cannot be done.

\section{Case report}

A 50 years old male Rickshaw driver visited to out patient department of CBMCB with the complaints of painless, multinodular mass in the right upper eyelid for the last two years. At first it was a single nodule and got surgical treatment in local eye hospital as chalazion but the nodule enlarged again. Thereafter he also was treated as incision \& curettage by another doctor about one year back. It was gradually increased upto the present size. He gave no history of Pain, Redness, or Discharge from the growth. On examination the best corrected visual acuity was $6 / 6$ in both eyes.

\footnotetext{
1. *Dr. Mahmudul Hasan Siddiqi. Assistant Professor, Dept. of Ophthalmology, CBMCB.

2. Prof. Dr. Mirza Hamidul Huq Head of the Dept. of Pathology, CBMCB

3. Dr. Ambia Begum Assistant Prof. Dept. of Pathology, CBMCB

4. Dr. Fazilatunnesa Assistant Prof. Dept. of Pathology, CBMCB
}

Address of Corresponds : Email : siddiqia74@yahoo.com Mobile :+88 01722-850136 


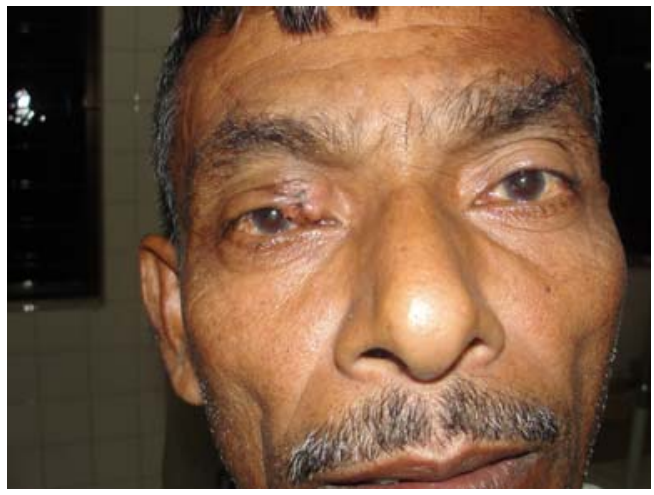

Fig.: 1 showing clinial picture of adenocarcinoma of meibomian gland.

There was a multinodular mass in the medial side of the right upper eye lid measuring $1 \mathrm{~cm} / 1 \mathrm{~cm}$, deep brown in color ,medial side of the lid distorted with loss of eyelashes, Consistancy was firm to hard. Adjacent skin around the tumor showed indurations but rest of the lid skin was normal and movable. On everton palpebral conjunctiva showed papillary congestion and incision mark over the tarsal plate. Slit lamp examination of the right eye showed congested bulbar conjunctiva. Rest of the anterior and posterior segment structures found to be normal. The opposite eyelid, anterior segment, pupillary reflex and fundus examination were normal. Ocular motility was full in all gases. No palpable lymph node at the neck region, $\mathrm{He}$ had no history of injury or Radiation. Thorough systemic examination revealed no abnormality. All routine blood examination along with liver and renal function was also normal. As the growth suspected as malignancy, full thickness excision of the mass along with intact tissue was done and that was reconstructed carefully and successfully by lid sharing procedure. At first tried by Mastarde rotation flap but planning changed due to excision of the lid $>50 \%$, so reconstruction completed with lid sharing procedure. Posterior lamella formed from lower eyelid and anterior lamella formed by full thickness skin graft from right arm. The conjunctiva was apposed with $8 / 0$ silk, muscle and skin in separate layers by $6 / 0$ vicryl. Eye bandage given after installation of antibiotic drop and ointment. Biopsy sample sent for
Histopathological examination and confirmed as Adenocarcinoma of the Meibomian gland of the right upper eye lid.

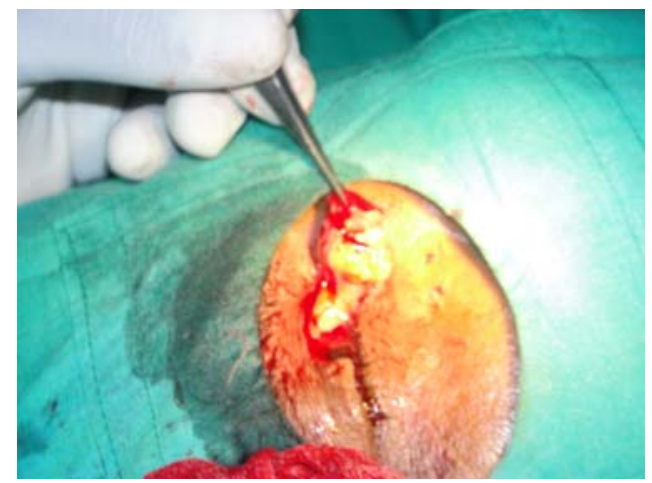

Fig. - 2 showing surgical Excision of tumour

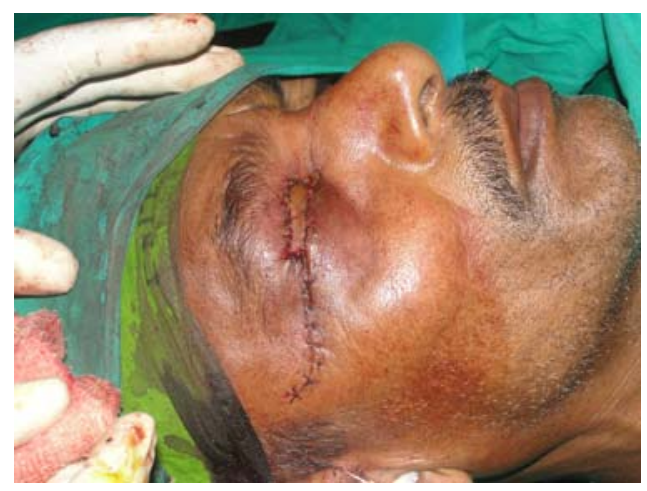

Fig. -03 showing lid Reconstraction completed after surgical procedure

The nasal, temporal, and upper borders of the supplied tissue were tumor free. Histopathological section shows anaplastic epithelial cells arranged in glandular with extensive area of necrosis of central portion of duct like tubular tissue. Mitotic figures are increased. 


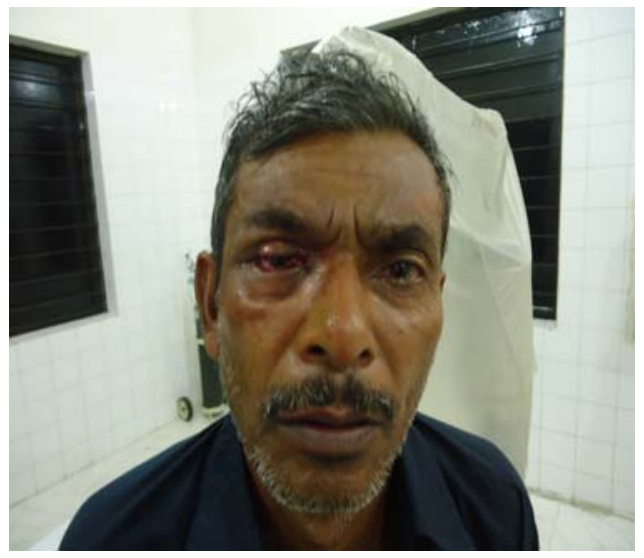

Fig. -04 showing recovery of the patient after one month.

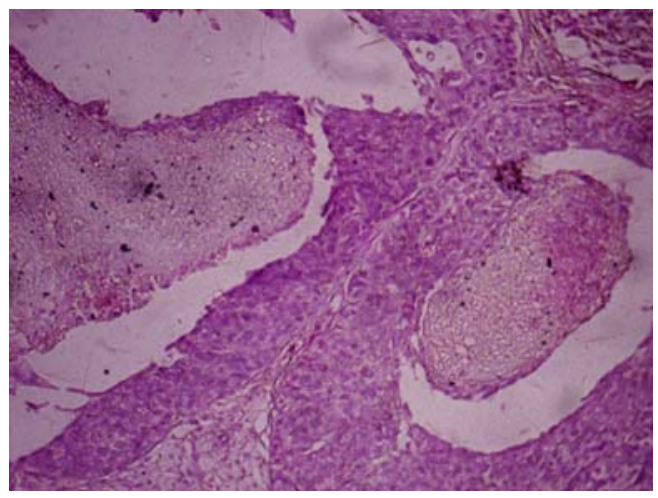

Fig.-05 showing histopathological picture of adnocarcinoma of meibomian gland

The reconstructed lid healed rapidly. The both lids opened after one month. The patient regained good lid function without cosmetic disfigurement. That large mass was managed successfully due to proper diagnosis and skilled surgical technique.

\section{Discussion}

Though the prevalence of Adenocarcinoma of the Meibomian glands are rare ,its prognosis is very bad in later cases and highly metastatic. Mortality rate is very $\mathrm{high}^{1}$. They are more frequent in female in elderly and occur more frequently in the upper lid due to its more glandular distribution there ${ }^{5-8}$.

However, in this case report the patient is male, tumor involves the upper eyelid.. Adenocarcinoma of the meibomian glands are commonly misdiagnosed clinically as well as histopathologically because of variable history and presentations ${ }^{9}$.

Usually they are insidious onset, painless ,firm eyelid mass . This type of patients most frequently get treatment for Chronic chalazion with recurrence later on. They can also mimic unilateral blerpheroconjunctivitis, meibomianitis, ocular cicatricial phamphigoid, basal or squamous cell carcinoma, superior limbic keratoconjunctivitis ${ }^{10}$. The tumour may spread to surrounding structures as well as blood $^{11}$.

Misdiagnosis is common in such a case. So recurrent and elderly presentations need confirmation by biopsy ${ }^{7}$. They can be managed well by wide surgical excision of the growth with normal tissue ${ }^{8}$.

In our case surgical excision was completed with histopathologically clear tissue margins.

Radiotherapy can be considered only for too ill patients or those who refuse for surgery. Exenteration may save life in case of orbital extention of the tumor.

Lid reconstruction surgery is very important after every surgical excision ${ }^{12-13}$. For the defect $<40 \%$ or $<1 / 3$ of lid a direct closure. Defect $>1 / 3$ to $1 / 2$ need Masturede check rotation flape. And $>1 / 2$ need lid sharing procedure like our case. Usually such cases responds well to surgical excision.

\section{Conclusion}

Since adenocarcinoma of the Meibomian gland can be mimic many other ocular condition, it needs to evaluate properly \& carefully for early detection and managemnt. Surgical excision of growth and lid reconstruction which may lead to better outcome and increases the survival rate.

\section{Acknowledgement;}

I am grateful to our Principal Professor Dr. Mirza Hamidul Huq, Head of the Dept of Pathology CBMCB and other colleagues for their help. 


\section{References}

1. Marlis Z, Hintschich CR, Garner A, et al. Sebaceous carcinoma of the eyelid: a clinicopathological study $\mathrm{Br} \mathrm{J}$ Ophthalmol. 1998; 82: 1049-55.

2. Johnson S, Nerad J, Syed N. Sebaceous Cell Carcinoma: A Masquerade Syndrome. Eye rounds.

3. Kass LG, Hornblass A. Sebaceous carcinoma of the ocular adnexa. Surv Ophthalmol. 1989; 33: 477-90.

4. Boniuk M, Zimmerman LE. Sebaceous carcinoma of the eyelid, eyebrow, caruncle, and orbit. Trans Am Acad Ophthalmol Otolaryngol. 1968; 72: 619-41.

5. Kass LG, Hornblass A. Sebaceous carcinoma of the ocular adnexa. Surv Ophthalmol. 1989; 33: 477-90.

6. Rao NA, McLean JW, Zimmerman LE. Sebaceous carcinoma of the eyelid and caruncle: Correlation of clinicopathologic features with prognosis. In Jakobiec FA (ed): Ocular and Adnexal Tumors. Birmingham, Aesculapius. 1978, 461-76.

7. Doxanas MT, Green WR. Sebaceous gland carcinoma: Review of 40 cases. Arch Ophthalmol. 1984; 102: 245-9.

8. Wolfe JT III, Yeatts RP, Wick MR, et al. Sebaceous carcinoma of the eyelid: Errors in clinical and pathologic diagnosis. Am J Surg Pathol. 1984; 8: 597- 606.

9. Awan KJ. Sebaceous carcinoma of the eyelid. Ann Ophthalmol. 1977; 9: 608

10. Yeatts RP, Waller RR. Sebaceous carcinoma of the eyelid: Pitfalls in diagnosis. Ophthalmic Plastic Reconstructive Surgery. 1985; 1: 35-42.

11. Khan JA, Doane JF, Grove AS Jr. Sebaceous and meibomian carcinomas of the eyelid. Recognition, diagnosis, and management. Ophthal Plast Reconstr Surg. 1991; 7: 61-6.

12. Khan SA,.Burney JA. Reconstruuction of lower lid following Sebaceous carcinoma-another case report. J. Pak. Acd. Ophthalmol. 1987; 2: 42-5.

13. Putterman AM. Basic Oculoplastic Surgery. In: Principles and Practice of Ophthalmology 1st ed. Philadelphia: W.B. Saunders. 1980, 33: 2292-3. 